\title{
A pilot study on maternal oral health and birth weight of twins
}

\author{
Ye Shen ${ }^{1}$, Chao Li ${ }^{1}$, Aura Heimonen², Jukka H. Meurman², Martha E. Nunn³, Donald R. Miller ${ }^{4}$, \\ Thomas E. Van Dyke ${ }^{5}$, Prashanti Bollu ${ }^{6}$, Risto Kaaja ${ }^{7}$, Sok-Ja Janket ${ }^{8^{*}}$
}

\footnotetext{
${ }^{1}$ Department of Epidemiology and Biostatistics, University of Georgia, Athens, USA

${ }^{2}$ Institute of Dentistry, University of Helsinki and Helsinki University Central Hospital, Helsinki, Finland

${ }^{3}$ Department of Periodontics, Creighton University School of Dentistry, Omaha, USA

${ }^{4}$ Department of Epidemiology, Boston University School of Public Health, Boston, USA

${ }^{5}$ Center for Periodontology, The Forsyth Institute, Boston, USA

${ }^{6}$ College of Dental Medicine, Roseman University of Health Sciences, Henderson, USA

${ }^{7}$ Satakunta Central Hospital and Turku University, Turku, Finland

${ }^{8}$ Department of General Dentistry, Boston University School of Dental Medicine, Boston, USA

Email: skjanket@bu.edu
}

Received 9 November 2013; revised 9 December 2013; accepted 16 December 2013

Copyright $(0) 2014$ Ye Shen et al. This is an open access article distributed under the Creative Commons Attribution License, which permits unrestricted use, distribution, and reproduction in any medium, provided the original work is properly cited. In accordance of the Creative Commons Attribution License all Copyrights (C) 2014 are reserved for SCIRP and the owner of the intellectual property Ye Shen et al. All Copyright (C) 2014 are guarded by law and by SCIRP as a guardian.

\section{ABSTRACT}

Background: Oral health has been implicated in low birth weight or preterm birth. However, this relationship has not yet been studied in twins. We investigated whether maternal oral health was associated with the birth weights of twins by a cross-sectional study conducted at Helsinki University Central Hospital. Methods: Utilizing linear mixed effect models to recognize the correlation between twins from the same mothers and the independence between different mothers. 40 birth weights of twins were modeled as main outcomes. In model 1 , poor periodontal health (PPH) was fitted as the main explanatory variable. In model 2, presence of non-specific oral mucositis (NSOM) was fitted as the main predictor. Results: In model 1, babies from mothers with PPH weighed approximately 158.2 grams less than babies of mothers without PPH. However, this association was not statistically significant $(p=0.11)$. When a stricter criterion for PPH (3 sites of pocket depth $>4$ $\mathrm{mm}$ ) was used, p-value decreased to 0.09 showing a dose response to $\mathrm{PPH}$. In model 2, mothers with NSOM had babies weighing 224.9 grams less than mothers without these lesions. This was nearly significant ( $p=0.08)$. Conclusion: Although not significant, the results from this small data of twins suggest that maternal oral health may be associated with birth weight of twin neonates. Our results are appropriate to generate hypothesis for future studies.

\footnotetext{
${ }^{*}$ Corresponding author.
}

\section{KEYWORDS}

Twins; Birth Weights; Oral Health; Correlated Data; Linear Mixed Effect Models

\section{INTRODUCTION}

The incidence of multiple gestation was estimated to be between 13.3 - 14.8 per 1000 live births in 1998, accounting to about $1.4 \%$ in Europe and $1.9 \%$ in the US [1]. At least $50 \%$ of twins are born before 37 weeks or with a birth weight less than 2500 gm [2]. Thus, multiple birth is a major risk factor for low birth weight and/or preterm birth. Increasing utilization of fertility treatment and advancing maternal age at pregnancy are known contributing factors to multiple birth and thereby to preterm/low birth weight [3]. However, little is known about risk factors for multiple gestations or the possible role of oral health on these risk factors.

Twin gestation results from the following mechanism. Dizygosity occurs in about 2/3 of twins and is the result of fertilization of two oocytes developing into dichorionic and diamniotic twins. Monozygosity occurs when one oocyte fertilizes but cleaves during the mitotic process. Depending on the time of division, the monozygosity may have monochorionic or dichorionic placentation. Although infant mortality and morbidity increases with twin gestation, the risk varies depending more on chorionicity than zygosity [4].

Maternal infections including intra- and extra-uterine infection have been implicated in the etiology of preterm 
birth or low birth weight through the activation of the innate immune system leading to increased expression of prostaglandins and other inflammatory cytokines $[5,6]$. We postulated that open sores on the oral mucosa may become a portal for the hematogenous translocation of pathogens or provide pathways for inflammatory mediators and may induce similar expression of prostaglandins and other inflammatory cytokines as periodontitis. Although research of infection and/or immunity dissemination via oral mucosa is relatively new in dental research, many reports of viral or bacterial dissemination through mucosa have been documented in medicine [7-9].

In addition to infection, other known determinants of newborn weight include maternal diabetes/insulin resistance which is known to be associated with larger for the gestational age baby [10] and macrosomia [11], while maternal smoking causes smaller for gestational age baby [12]. The single most important determinant of birth weight is gestational age of the neonates. However, most risk factors for preterm birth identified in singleton birth were not as informative and relevant in twin gestation [13]. Furthermore, the relationship between maternal oral health and birth weight of neonates has never been investigated in the twin population. Thus we embarked the current study to explore this relationship in twin gestation.

A more sophisticated statistical manipulation and application is required in the analyses of twin data. Birth weights of twins from the same mothers are correlated while the same from different mothers are independent. Thus, recognizing this unique statistical challenge in statistics, we sought to explore whether, maternal oral infections are associated with the birth weight of twins while simultaneously controlling for gestational age (in days), smoking, and diabetes. We used linear mixed models which recognize the correlated nature of twins' birth weight from the same mother and independence from difference mothers $[14,15]$ to study the relationship between maternal oral infections as the predictors and the birth weights of twins as the outcome.

This study has two specific aims: one was to study the association between maternal poor periodontal health (PPH) $[14,15]$ and baby weights; the other was to study the association between maternal non-specific oral muscositis (NSOM) status and baby weights. The objectives were to investigate if maternal oral infections were associated with twin birth weights and to provide basic rationale in hypothesis generation for future studies.

\section{MATERIALS AND METHODS}

\subsection{Evolvement of the Cohort}

A total of 482 women who had given birth at the Department of Gynaecology and Obstetrics, Helsinki Uni- versity Central Hospital (HUCH) in Finland between September 2002 and May 2004 were invited to participate in the study. The study nurse recruited participants and those interested provided a written consent. Primary exclusion criteria were illicit drug abuse and infection with hepatitis B, hepatitis C or HIV. Out of 482 women, 25 gave birth to twins of which we further excluded 5 women who had dental examination at an unknown time. Thus a cross-sectional study was conducted among 20 women who gave birth to twins and had a dental examination in the hospital 2 - 3 day post-partum.

\subsection{Ethical Consideration}

The study was approved by the Ethics Committee and Institutional Review Board of the Helsinki University Central Hospital (HUCH).

\subsection{Clinical Oral Examination and Assessment of the Predictor}

Mothers were examined by two experienced dentists within 2 days postpartum in a specially equipped dental office at the hospital. For those who were too tired to come to the examination room, a bed-side examination was given using an ontological light source. Presence of pregnancy complications was blinded to the examiners. The examiners measured Periodontal probing depth (PD) by using a calibrated probe at six sites per tooth on all teeth. Gingival bleeding on probing (BOP) and teeth with visible dental plaque were recorded at four sites per tooth on all teeth (plaque index). The examiners were not calibrated but they both were employees of the City of Helsinki Health Department where regular diagnostic meetings served as calibration sessions.

We defined maternal poor periodontal health as 1 if the women had more than 1 site of deep periodontal pocket (>= $4 \mathrm{~mm}$ ) and $30 \%$ of surfaces with gingival bleeding modified criteria used by Radnai et al. and Lunardelli and Peres $[14,15]$. Non-specific oral mucositis was defined as any open sores, namely a breach on the oral mucosa, including aphthous ulcers, herpes simplex or trauma from cheek biting or tooth brushing where potential pathogens or pro-inflammatory mediators could disseminate. No one in this cohort had red leukoplakia or white lesions.

\subsection{Maternal Characteristics}

In addition to the clinical dental examination, the participants completed a questionnaire reporting important health and lifestyle related behaviours. Smoking was recorded as past, current, or never smokers. Frequency of alcohol consumption during pregnancy was recorded. Data on demographic factors, prenatal care, medical and 
obstetrical history were obtained from medical records. Body mass index (BMI) and weight gain between the first and the third trimester were calculated from anthropometric measurements. The number of previous pregnancies including spontaneous miscarriages, PLBW births and stillbirths as well as information on complications such as infections and pre-eclampsia was recorded.

\subsection{Assessment of the Outcome}

Gestational age was determined based on the date of the last menstrual period and confirmed by ultrasound examination between 11 - 14 weeks of gestation. The weights of neonates were recorded immediately after delivery. Contingent on the correlated nature of weights of twins from the same mother and independence from different mothers, we collected 40 birth weights of twins.

\subsection{Statistical Methods}

Using SAS 9.1 we calculated means and standard deviations for the continuous variables and Fishers exact test for categorical variables in univariate analyses. A significance level of 0.05 is used throughout the paper.

For multivariate analyses, we used proc mixed format, which is under the umbrella of Generalized Estimate Equations where each correlated or repeated measure is considered data point. Thus, 20 women provided 40 birth weights of twins and linear mixed effect models were fitted. Linear mixed models appropriately recognize the correlated relationship of twins from the same mother and the independence of the baby weights from different mothers. We compared the birth weights of neonates in $\mathrm{PPH}$ group and non-PPH group in model 1 and also in the group with NSOM and non-NSOM in model 2.

Linear mixed effect models require normality of the outcomes distribution. Due to the relatively small sample size $(\mathrm{N}=40)$ in this study, the normality assumption of the outcomes (baby weights) needed to be verified. From the histograms in Figure 1, we can visually verify that the outcomes (birth weight) appeared to be normally distributed. For a formal test, the Kolmogorov-Smirnov test was conducted and generated a chi-square statistic at 0.102 with $\mathrm{P}$ value $>0.15$, thus the assumption of normality of baby weights was appropriately satisfied.

Due to the small sample size $(\mathrm{N}=40)$, only the most important confounders namely maternal diabetes, smoking status, and gestational age of the twins were controlled and thus were included in the model as covariates. Unstructured covariance structure was chosen because the model appeared fitting better than compound symmetry covariance.

\section{RESULTS}

The median gestational age at birth was 253 days and

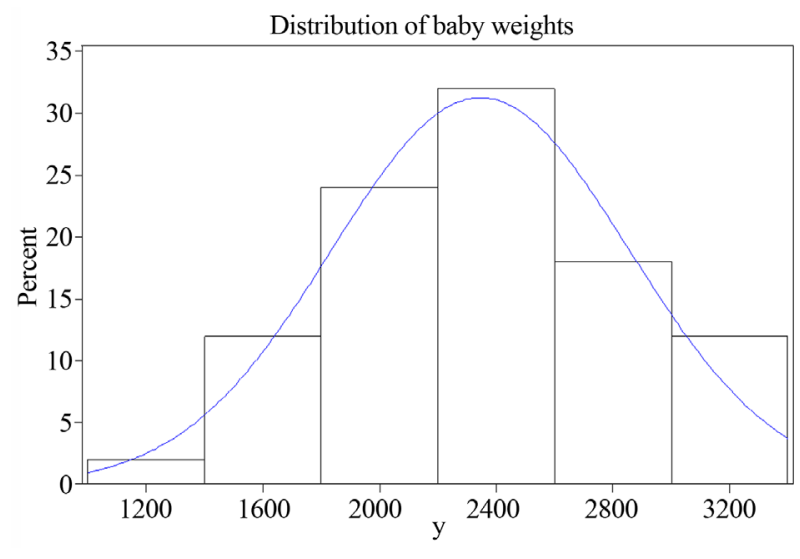

Figure 1. Histogram for the distribution of baby weights.

$75 \%$ of births occurred on or before 263 days of gestation. Thus, the definition of preterm birth for singleton standard may not be appropriate in twins. The average weights of twins were 4517.33 grams \pm 539.5 in women with poor periodontal health (PPH) and 4717.3 grams \pm 1102.9 in women with better periodontal health respectively, resulting a net decrease of 158.2 grams (adjusted in model 1 as shown in Table 2) of baby's weight in mothers with $\mathrm{PPH}$. Similarly, the babies from women with NSOM weighed 4461.2 grams \pm 547.2 compared with the babies from mothers without NSOM at 4678.5 gram \pm 987.5 , resulting in a net decrease of 224.9 grams (adjusted in model 2 as shown in Table 3) of mean baby's weight in mothers with NSOM. Although these weight decreases were not statistically significant, these results suggest oral infection may affect twin neonates' weight. None of the participants had type 1 or type 2 diabetes prior to this pregnancy but two women developed gestational diabetes. Nine women satisfied the definition of poor periodontal health $(\mathrm{PPH})$ for the current study i.e. 1 or more sites of pocket deeper than $4 \mathrm{~mm}$ and $30 \%$ or more surfaces with gingival bleeding. Of these nine women, six women had 3 or more sites of deep pockets.

The basic characteristics of all 20 women are presented in Table 1 . None of the variables in Table 1 were significantly different between the groups except gender discordant (male and female twins). In previous twin studies, gender discordant and weight discordant were found to be associated with preterm birth.

Fourteen (70\%) of the 20 women included in our study had preterm birth at 37 weeks of gestation or less, and 6 women had full term births. Of the 14 women who had preterm delivery, 8 (57.1\%) had poor periodontal health (PPH) and 4 (28.6\%) had non-specific oral mucositis (NSOM). Of the 6 women who delivered at full term, only 1 (16.7\%) had PPH and none had NSOM. Both women who developed gestational diabetes (GDM) had PPH. GDM was evenly divided between NSOM and 
Table 1. General characteristics of the cohort $(\mathrm{N}=20)$.

\begin{tabular}{|c|c|c|c|c|}
\hline College & New students & Graduating students & Change & \\
\hline Parameter & $\begin{array}{c}\mathrm{PPH}^{*}=0(\mathrm{~N}=11) \\
(22 \text { babies })\end{array}$ & $\begin{array}{l}\mathrm{PPH}=1(\mathrm{~N}=9) \\
\quad(18 \text { babies })\end{array}$ & $\begin{array}{c}\mathrm{NSOM}^{\dagger}=0(\mathrm{~N}=16) \\
(32 \text { babies })\end{array}$ & $\begin{array}{c}\mathrm{NSOM}=1(\mathrm{~N}=4) \\
\quad(8 \text { babies })\end{array}$ \\
\hline Age (Mean \pm SD) & $31.0( \pm 5.5)$ & $32.4( \pm 4.9)$ & $31.6( \pm 5.5)$ & $32.0( \pm 4.2)$ \\
\hline Body Mass Index (Mean \pm SD) & $21.8( \pm 2.01)$ & $24.0( \pm 6.3)$ & $23.1( \pm 5.0)$ & $21.4( \pm 1.6)$ \\
\hline Maternal weight gain $(\mathrm{Kg})$ & $16.1( \pm 3.6)$ & $17.3( \pm 7.5)$ & $16.9( \pm 5.4)$ & $15.0( \pm 7.1)$ \\
\hline Mean gestational days & $247( \pm 19.9)$ & $247( \pm 7.7)$ & $247( \pm 16.9)$ & $249( \pm 6.6)$ \\
\hline Sum of twin's weights (Mean \pm SD (gm)) & $4717.3 \pm 1102.9$ & $4517.3 \pm 539.5$ & $4678.5 \pm 987.5$ & $4461.2 \pm 547.2$ \\
\hline $\begin{array}{l}\text { Smoking, N (\%) Ever } \\
\text { - } \quad \text { No } \\
\text { - } \quad \text { Yes }\end{array}$ & $\begin{array}{l}8(73 \%) \\
3(27 \%)\end{array}$ & $\begin{array}{l}6(67 \%) \\
3(33 \%)\end{array}$ & $\begin{array}{l}12(75 \%) \\
4(25 \%)\end{array}$ & $\begin{array}{l}2(50 \%) \\
2(50 \%)\end{array}$ \\
\hline $\begin{array}{l}\text { Current } \\
\text { - No } \\
\text { - } \quad \text { Yes }\end{array}$ & $\begin{array}{c}11(100 \%) \\
0\end{array}$ & $\begin{array}{l}8(89 \%) \\
1(11 \%)\end{array}$ & $\begin{array}{c}15(94 \%) \\
1(6 \%)\end{array}$ & $\begin{array}{c}4(100 \%) \\
0\end{array}$ \\
\hline $\begin{array}{l}\text { Anti-microbial treatment } \\
\text { - No } \\
\text { - Yes }\end{array}$ & $\begin{array}{l}9(82 \%) \\
2(18 \%)\end{array}$ & $\begin{array}{l}8(89 \%) \\
1(11 \%)\end{array}$ & $\begin{array}{c}13(82 \%) \\
3(8 \%)\end{array}$ & $\begin{array}{c}4(100 \%) \\
0(0 \%)\end{array}$ \\
\hline $\begin{array}{l}\text { Gynecological infection } \\
\text { - No } \\
\text { - Yes }\end{array}$ & $\begin{array}{l}9(82.8 \%) \\
2(18.2 \%)\end{array}$ & $\begin{array}{c}9(100 \%) \\
0(0 \%)\end{array}$ & $\begin{array}{c}14(87.5 \%) \\
2(12.5 \%)\end{array}$ & $\begin{array}{c}4(100 \%) \\
0(0 \%)\end{array}$ \\
\hline $\begin{array}{l}\text { Infertility treatment } \\
\text { - No } \\
\text { - } \quad \text { Yes }\end{array}$ & $\begin{array}{l}9(82.8 \%) \\
2(18.2 \%)\end{array}$ & $\begin{array}{l}7(77.8 \%) \\
2(22.2 \%)\end{array}$ & $\begin{array}{c}14(87.5 \%) \\
2(12.5 \%)\end{array}$ & $\begin{array}{l}2(50 \%) \\
2(50 \%)\end{array}$ \\
\hline $\begin{array}{l}\text { Primiparity } \\
\text { - } \quad \text { No } \\
\text { - } \quad \text { Yes }\end{array}$ & $\begin{array}{l}5(45 \%) \\
6(55 \%)\end{array}$ & $\begin{array}{l}6(67 \%) \\
3(33 \%)\end{array}$ & $\begin{array}{c}10(63 \%) \\
6(37 \%)\end{array}$ & $\begin{array}{l}1(25 \%) \\
3(75 \%)\end{array}$ \\
\hline $\begin{array}{l}\text { Gestational Diabetes, N (\%) } \\
\text { - } \quad \text { No } \\
\text { - } \quad \text { Yes }\end{array}$ & $\begin{array}{c}11(100 \%) \\
0\end{array}$ & $\begin{array}{l}7(78 \%) \\
2(22 \%)\end{array}$ & $\begin{array}{c}15(94 \%) \\
1(6 \%)\end{array}$ & $\begin{array}{l}3(75 \%) \\
1(25 \%)\end{array}$ \\
\hline Number of bleeding surfaces (mean \pm SD) & $12.9 \pm 9.4$ & $45.7 \pm 15.3$ & $23.1 \pm 20.0$ & $45.7 \pm 12.0$ \\
\hline Number of plaque-covered surfaces (mean $\pm \mathrm{SD}$ ) & $15.7 \pm 20.1$ & $37.7 \pm 28.8$ & $18.1 \pm 9.8$ & $55.5 \pm 30.4$ \\
\hline $\begin{array}{l}\text { Ever drink } \\
\text { - } \quad \text { No } \\
\text { - } \quad \text { Yes }\end{array}$ & $\begin{array}{l}8(73 \%) \\
3(27 \%)\end{array}$ & $\begin{array}{c}9(100 \%) \\
0\end{array}$ & $\begin{array}{c}13(81 \%) \\
3(19 \%)\end{array}$ & $\begin{array}{c}4(100 \%) \\
0\end{array}$ \\
\hline $\begin{array}{l}\text { (Table } 1 \text { cont’d) Weight discordant }{ }^{\S} \mathrm{N}(\%) \\
\text { - } \quad \text { No } \\
\text { - } \quad \text { Yes }\end{array}$ & $\begin{array}{l}6(55 \%) \\
5(45 \%)\end{array}$ & $\begin{array}{l}7(78 \%) \\
2(22 \%)\end{array}$ & $\begin{array}{c}10(63 \%) \\
6(37 \%)\end{array}$ & $\begin{array}{l}3(75 \%) \\
1(25 \%)\end{array}$ \\
\hline $\begin{array}{l}\text { Gender discordant }{ }^{\|}(\%) \\
\text { - } \quad \text { No } \\
\text { - } \quad \text { Yes }\end{array}$ & $\begin{array}{c}11(100 \%) \\
0\end{array}$ & $\begin{array}{c}\mathrm{P}<0.002^{* *} \\
3(33 \%) \\
6(67 \%)\end{array}$ & $\begin{array}{c}13(81 \%) \\
3(19 \%)\end{array}$ & $\begin{array}{c}\mathrm{P}<0.06^{* *} \\
1(25 \%) \\
3(75 \%)\end{array}$ \\
\hline
\end{tabular}

"PPH: poor periodontal health (more than 1 sites of $4 \mathrm{~mm}$ or deeper pocket and $30 \%$ surfaces of gingival bleeding; ${ }^{\dagger} \mathrm{NSOM}$ : maternal non-specific oral mucositis status; ${ }^{\ddagger}$ Primiparity: first baby; ${ }^{\S}$ Weight discordant: twin’s weights differ more than $25 \%$ in the same mother. "Gender discordant: twins have different gender in the same mother. ${ }^{* *}$ Only gender discordant was significant or nearly significant by Fisher's exact test. • Some variables have $\mathrm{N}<20$ due to missing values.

non-NSOM.

Table 2 shows the results of the linear mixed effect regression model for association between baby weights and periodontitis. Babies from mothers without $\mathrm{PPH}$ weighed 183.0 grams more than babies from mothers with PPH on average ( $p=0.11)$. When we used stricter periodontitis definition ( $\geq 3$ sites of periodontal pocket deeper than $4 \mathrm{~mm}$ ), the p-value decreased to 0.09. This is suggestive of dose response of periodontal health to baby's weight. As for the three confounders under study, maternal diabetes and gestational age were significantly associated with twins' birth weights with $\mathrm{p}<0.0001$ and $\mathrm{p}=0.007$ respectively, while no significant association was found for smoking status $(\mathrm{p}=0.48)$ and baby's weight. Although not significant, babies from current smoking women weighed 310 gm less than babies from 
Table 2. Results of the linear mixed effect regression model for association between baby weights and periodontitis.

\begin{tabular}{|c|c|c|c|c|}
\hline \multicolumn{5}{|c|}{ Solution for Fixed Effects } \\
\hline Effect & & $\begin{array}{c}\text { Parameter } \\
\text { estimate (gm) }\end{array}$ & $\begin{array}{l}\text { Standard } \\
\text { error }\end{array}$ & P-value \\
\hline \multirow[t]{2}{*}{$\mathrm{PPH}^{*}$} & 0 & 158.2 & 94.5 & 0.11 \\
\hline & 1 & 0 & & \\
\hline Gestional age $^{\dagger}$ & (per day) & 26.3 & 3.3 & $<0.0001$ \\
\hline \multirow{2}{*}{ Current smoker $^{*}$} & 0 & 330.7 & 232.4 & 0.48 \\
\hline & 1 & 0 & & \\
\hline \multirow[t]{2}{*}{ Gestdiab $^{\dagger *}$} & 0 & -424.1 & 174.2 & 0.007 \\
\hline & 1 & 0 & & \\
\hline
\end{tabular}

${ }^{*} \mathrm{PPH}$ : Poor periodontal health indicator (binary) variable; ${ }^{\dagger}$ Gestday: gestational age in days; ${ }^{\ddagger}$ Gestdiab: gestational diabetes.

non-smoking mothers.

Table 3 shows the results of the linear mixed effect regression model for association between baby weights and mucositis. Marginally significant difference was found between NSOM and baby weights $(\mathrm{p}=0.08)$. Babies from mothers without mucositis weighed 224.9 grams more than babies from mothers with mucositis on average. Similar to the PPH model, the gestational age and maternal diabetes in NSOM model were significantly associated with baby weights $(\mathrm{p}<0.0001$ and $\mathrm{p}=$ 0.005 respectively, while no significant association was found for smoking status ( $\mathrm{p}=0.18)$.

Gestational diabetes mellitus (GDM) was not associated with PTB in our previous study on singletons [16]. However, it strongly affected baby weights in the current study. As shown in both PPH and NSOM model, maternal diabetes was significantly associated with baby weights (both $p$ values < 0.0001). Babies from GDM women weighed over $500 \mathrm{gm}$ more than non-GDM women.

Another strong determinant of babies' weight was the gestational age. In model 1 , for each day of gestation, babies gained $23.3 \mathrm{gm}$ on average ( $<0.0001)$, while in model 2, babies gained 24.3 gm on average $(\mathrm{p}<0.0001)$ for each day of gestation.

\section{DISCUSSION}

In this convenience sample of twins, we observed a correlation between lower birth weight and poor oral health. In the multivariate analyses, after controlling for gestational age at birth, maternal diabetes, assisted reproductive treatment and maternal smoking, we found marginally significant results for the association between maternal oral health and birth weight.

Although it is possible that our results may be a ma-
Table 3. Results of the linear mixed effect regression model for association between baby weights and non-specific oral mucositis.

\begin{tabular}{|c|c|c|c|c|}
\hline \multicolumn{5}{|c|}{ Solution for Fixed Effects } \\
\hline Effect & & $\begin{array}{c}\text { Parameter } \\
\text { estimate (gm) }\end{array}$ & $\begin{array}{l}\text { Standard } \\
\text { error }\end{array}$ & P-value \\
\hline \multirow{2}{*}{$\mathrm{NSOM}^{\S^{*}}$} & 0 & 224.9 & 121.3 & 0.08 \\
\hline & 1 & & & \\
\hline Gestional age $^{\dagger}$ & (per day) & 24.3 & 3.2 & $<0.0001$ \\
\hline \multirow{2}{*}{ Current smoker ${ }^{*}$} & 0 & 310.3 & 218.4 & 0.18 \\
\hline & 1 & & & \\
\hline \multirow[t]{2}{*}{ Gestdiab $^{\dagger *}$} & 0 & -525.4 & 161.6 & 0.005 \\
\hline & 1 & & & \\
\hline
\end{tabular}

${ }^{\S}$ NSOM: Non-specific oral Mucositis; ${ }^{\dagger}$ Gestional age: in days; ${ }^{\ddagger}$ Gestdiab: gestational diabetes.

nifestation of a spurious association, they certainly provide sufficient evidence to generate a hypothesis for future study. Since the data was collected by two different groups of healthcare professionals who had no knowledge of the predictor (maternal oral health), or the outcome (birth weight), selection bias could not have affected our results.

Our results indicate that maternal diabetes was associated with macrosomia and may affect the nutritional environment of the fetus, causing significant weight gains in those babies from diabetic mothers. 7, 8 However, in our singleton studies, GDM was not a significant determinant of preterm birth. 15 The fact that gender discordant was significantly associated with PPH and nearly significantly associated with NSOM suggests that oral infection may be a manifestation of hormonal changes clustering around sex difference of the twins; further research is warranted in this area.

One critical limitation of the current study is the small sample size, because of which, all potential confounding variables could not be adjusted, thus resulting in possible residual confounding. For instance, previous studies have verified that systemic infections such as pneumonia18, and genitourinary track infections like bacterial vaginosis, chlamydia trachomatis infections and syphilis, were all associated with PTB.5, 16, 17. These infections may co-exist with oral infections having potential interactions with each other, and NSOM may even be the result of these infections. However, this is a highly unlikely scenario because in univariate analyses, NSOM was neither significantly associated with antimicrobial treatment nor with genitourinary infections. When we fitted anti-microbial treatment in the model, we observed the evidence of model saturation generating improvable parameter estimates. 
Although our results did not reach the critical value of $\mathrm{p}<0.05$, $\mathrm{p}$ value should not be the only determinant of any research results. Gardner and Altman (1986) argued that overemphasis on hypothesis testing and the exaggerated trust on $\mathrm{P}$ values has detracted many from more useful approaches in clinical research. Rather, point estimates and confidence intervals offer more clinically meaningful inferences. However, considering the extremely small sample size $(\mathrm{N}=40)$, p-value 0.09 and 0.08 should be viewed as highly meaningful association $[17,18]$. Further study is needed to confirm our suggestive results.

It appears that current smoking had stronger effect on birth weight when there was an open sore (mucositis) in the oral cavity (Tables 2 and 3). Current smokers with PPH had babies weighing 166 gm less while current smokers with NSOM had babies weighing 310 gm less than non-current smokers. We postulated that smoking effects enter the systemic circulation easily when there is an open sore.

NSOM had slightly stronger association with birth weight than PPH. Babies from mothers without mucositis weighed 224.9 grams more than babies from mothers with mucositis on average, compared with the smaller margin of 183.0 grams for mothers with PPH on average. For the association between mucositis and birth weight, marginally significant difference was found between the groups $(p=0.08)$. In our singleton study, NSOM was negatively associated with maternal weight gain, and inadequate maternal weight gain was a strong risk factor for preterm birth. It is possible that mucositis may be an indicator of the poor nutritional state or undetected underlying disease (i.e. anemia, or leukemia), thus less optimal general health of the pregnant women.

A close look at Table 1 indicates a greater deviation from the mean in the non-PPH. This suggests that variability is less in PPH groups indicating uniformly poor periodontal health. By further exploring the original data, we got coefficient of variation (CV) for PPH and non-PPH groups as 0.03 and 0.08 accordingly. The small values of coefficient of variation (CV) for each group indicate that the gestational age data presented within is stable, and so the difference itself might be due to true random variation.

So far, no single index has been identified as the standard evaluation of oral health. We used PPH and NSOM to evaluate the patients' oral health. Further larger studies are needed to establish the etiologic role of oral health in adverse birth outcomes.

When we added assisted reproductive (infertility) treatment or zygosity to the models, we observed strong evidence of model saturation and instability. These factors should be addressed in a future large cohort.

\section{CONCLUSION}

Although not significant, the results from this small sample of twins appear to suggest that maternal oral health may be associated with birth weight of twin neonates. These results offer adequate evidence for hypothesis generation for future longitudinal study to elucidate whether periodontal health and/or non-specific oral mucositis is causally associated with the birth weight of twin neonates.

\section{REFERENCES}

[1] Martin, J.A. and Taffel, S.M. (1995) Current and future impact of rising multiple birth ratios on low birth weight. Statistical Bulletin-Metropolitan Insurance Companies, 76, 10-18.

[2] Blondel, B. and Kaminski, M. (2002) Trends in the occurrence, determinants, and consequences of multiple births. Seminars in Perinatology, 26, 239-249. http://dx.doi.org/10.1053/sper.2002.34775

[3] Schieve, L.A., Meikle, S.F., Ferre, C., Peterson, H.B., Jeng, G. and Wilcox, L.S. (2002) Low and very low birth weight in infants conceived with use of assisted reproductive technology [see comment]. New England Journal of Medicine, 346, 731-737. http://dx.doi.org/10.1056/NEJMoa010806

[4] Dube, J., Dodds, L. and Armson, B.A. (2002) Does chorionicity or zygosity predict adverse perinatal outcomes in twins? American Journal of Obstetrics \& Gynecology, 186, 579-583.

http://dx.doi.org/10.1067/mob.2002.121721

[5] Goldenberg, R.L., Culhane, J.F., Iams, J.D. and Romero, R. (2008) Epidemiology and causes of preterm birth. Lancet, 371, 75-84. http://dx.doi.org/10.1016/S0140-6736(08)60074-4

[6] Offenbacher, S. (2004) Maternal periodontal infections, prematurity, and growth restriction. Clinical Obstetrics \& Gynecology, 47, 808-821; Discussion 881-802.

[7] Tugizov, S., Herrera, R., Veluppillai, P., Greenspan, J., Greenspan, D. and Palefsky, J.M. (2007) Epstein-Barr Virus (EBV)-infected monocytes facilitate dissemination of EBV within the oral mucosal epithelium. Journal of Virology, 81, 5484-5496.

http://dx.doi.org/10.1128/JVI.00171-07

[8] Abel, K., Pahar, B., Van Rompay, K.K.A., Fritts, L., Sin, C., Schmidt, K., Colon, R., McChesney, M. and Marthas, M.L. (2006) Rapid virus dissemination in infant macaques after oral simian immunodeficiency virus exposure in the presence of local innate immune responses. Journal of Virology, 80, 6357-6367. http://dx.doi.org/10.1128/JVI.02240-05

[9] Abendroth, A., Morrow, G., Cunningham, A.L. and Slobedman, B. (2001) Varicella-zoster virus infection of human dendritic cells and transmission to T cells: Implications for virus dissemination in the host. Journal of Virology, 75, 6183-6192. http://dx.doi.org/10.1128/JVI.75.13.6183-6192.2001 
[10] Silverman BL, Rizzo T, Green OC, Cho NH, Winter RJ, Ogata ES, Richards GE and Metzger BE. (1991) Longterm prospective evaluation of offspring of diabetic mothers. Diabetes, 40, 121-125.

http://dx.doi.org/10.2337/diab.40.2.S121

[11] Tan, Y.Y. and Yeo, G.S. (1996) Impaired glucose tolerance in pregnancy-Is it of consequence? Australian \& New Zealand Journal of Obstetrics \& Gynaecology, 36, 248-255. http://dx.doi.org/10.1111/j.1479-828X.1996.tb02704.x

[12] Aagaard-Tillery, K.M., Porter, T.F., Lane, R.H., Varner, M.W. and Lacoursiere, D.Y. (2008) In utero tobacco exposure is associated with modified effects of maternal factors on fetal growth. American Journal of Obstetrics \& Gynecology, 198, e61-e66.

[13] Goldenberg, R.L., Iams, J.D., Miodovnik, M., Van Dorsten, J.P., Thurnau, G., Bottoms, S., Mercer, B.M., Meis, P.J., Moawad, A.H., Das, A., Caritis, S.N. and McNellis, D. (1996) The preterm prediction study: Risk factors in twin gestations. National Institute of Child Health and Human Development Maternal-Fetal Medicine Units Network. American Journal of Obstetrics \& Gynecology, 175, 1047-1053.

http://dx.doi.org/10.1016/S0002-9378(96)80051-2
[14] Lunardelli, A.N. and Peres, M.A. (2005) Is there an association between periodontal disease, prematurity and low birth weight? A population-based study. Journal of Clinical Periodontology, 32, 938-946. http://dx.doi.org/10.1111/j.1600-051X.2005.00759.x

[15] Radnai, M., Gorzo, I., Urban, E., Eller, J., Novak, T. and Pal, A. (2006) Possible association between mother's periodontal status and preterm delivery. Journal of Clinical Periodontology, 33, 791-796. http://dx.doi.org/10.1111/j.1600-051X.2006.00986.x

[16] Heimonen, A., Janket, S.J., Meurman, J.H., Furuholm, J., Ackerson, L.K. and Kaaja, R. (2008) Oral health care patterns and the history of miscarriage. Oral Diseases, 14, 734-740 http://dx.doi.org/10.1111/j.1601-0825.2008.01460.x

[17] Bahrami, H. (2005) The value of p-value. American Journal of Gastroenterology, 100, 1427-1428. http://dx.doi.org/10.1111/j.1572-0241.2005.41929 8.x

[18] Koehnle, T. (2005) The proof is not in the $P$ value. American Journal of Physiology-Regulatory Integrative \& Comparative Physiology, 288, R777; Author Reply R777-R778. 